\title{
Modelling of Insured Losses of Natural Catastrophes Using Block Maxima Model
}

\author{
Pavla Jindrová ${ }^{1, *}$, Viera Pacáková ${ }^{1}$, and Ivana Laštovičková ${ }^{1}$ \\ ${ }^{1}$ University of Pardubice, Faculty of Economics and Administration, Institute of Mathematics and Quantitative Methods, Studentská 95, \\ 53210 Pardubice, Czech Republic
}

\begin{abstract}
Catastrophic events have a huge impact on society as a whole. Insurance, or reinsurance is one way of reducing the economic consequences of catastrophic events. By Sigma Swiss Re criteria the event can be noted as a catastrophe when the economic losses, insured claims or casualties associated with an event exceed just one of the thresholds. These thresholds are updated every year. We can observe a growing trend in both the number of catastrophic events as well as in total economic losses and insured losses too. Risk management of insurance and reinsurance companies have to have available relevant information for estimation and adjusting premium to cover these risks. The aim of this article is to present one of the useful method - block maxima method. This method uses information from historical events about insured losses of natural catastrophes and estimates future insured losses. These estimates are very important for actuaries and for risk managers as it is one of the bases for calculating and adjusting premiums of products covering these types of risks.
\end{abstract}

\section{Introduction}

Catastrophic events are characterised by three main points: there are relatively rareness, there are statistical unexpected and there have huge impact on the whole society.

Table 1. Sigma event selection criteria for 2014-2017.

\begin{tabular}{|c|c|c|c|c|}
\hline $\begin{array}{c}\text { Insured losses } \\
\text { (in USD million) }\end{array}$ & $\mathbf{2 0 1 4}$ & $\mathbf{2 0 1 5}$ & $\mathbf{2 0 1 6}$ & $\mathbf{2 0 1 7}$ \\
\hline Maritime disasters & 19.6 & 19.7 & 19.9 & 20.3 \\
\hline Aviation & 39.3 & 39.3 & 39.8 & 40.7 \\
\hline $\begin{array}{c}\text { Other losses } \\
\text { or Total economic } \\
\text { losses }\end{array}$ & 48.8 & 48.8 & 49.5 & 50.5 \\
\hline \multicolumn{2}{|c|}{97.6} & 97.7 & 99.0 & 101.0 \\
\hline $\begin{array}{c}\text { or Casualties } \\
\text { Dead or missing }\end{array}$ & 20 & 20 & 20 & 20 \\
\hline \multicolumn{2}{|c|}{ Source: Sigma Swiss Re, [1-4] } \\
\hline Injured & 50 & 50 & 50 & 50 \\
\hline Homeless & 2000 & 2000 & 2000 & 2000 \\
\hline
\end{tabular}

* Corresponding author: Pavla.Jindrova@upce.cz
To classify as a catastrophe according to Sigma criteria [1-4], the economic losses, insured claims or casualties associated with an event must exceed just one of the thresholds, which are shown in Table 1 for years 2014-2017.

In Table 1 we can see, that values of these criteria are updated over time. Based on the values in Table 1, we see a growing trend in the values of insured and economic losses during the period under review. For example, total economic losses threshold increased from 97.6 USD million in 2014 to 101 USD million in 2017, this therefore represents increasing of this threshold by 2.5 USD million. The thresholds for the number of casualties remained constant over this period. For example, an event is classified as a catastrophic event if the number of deaths or missing people exceeds 20 persons.

We divide the catastrophic events into two groups according to their cause. The first are natural catastrophes caused by the effects of natural influences such as geological disasters, hydrological disasters, ... The second group consists of catastrophic events caused by human activity, i.e. man-made disasters, such as industrial disasters, traffic disasters, ...

Fig. 1 shows the number of catastrophic events in the period 1970-2017. We can see a growing trends in number of man-made disasters and number of natural catastrophes too. In terms of Sigma criteria, there were 301 catastrophes worldwide in 2017, down from 329 in 2016. There were 183 natural catastrophes (compared 
with 192 in 2016), and 118 man-made disasters (down from 137 in 2016). [4]

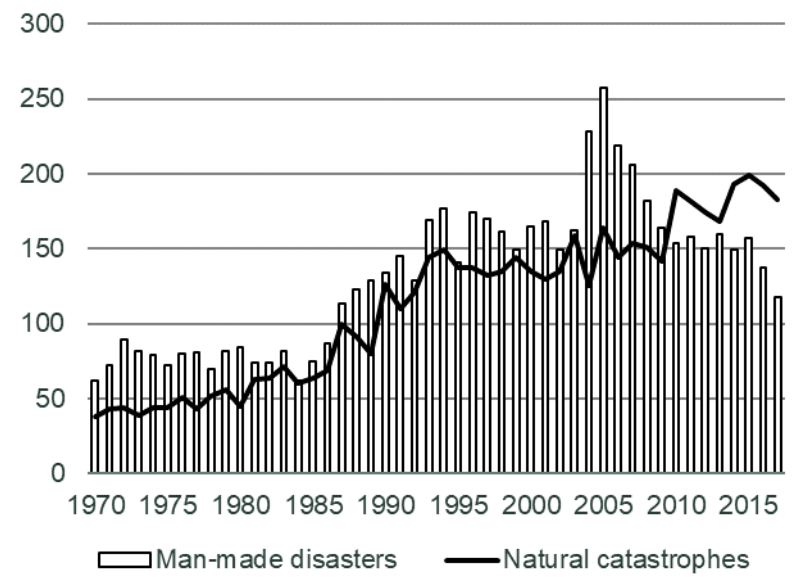

Source: Sigma Swiss Re, [4]

Fig. 1. Number of catastrophic events, 1970-2017

Fig. 2 shows the total economic losses by catastrophes. When we talk about total economic losses that means the sum of insured and uninsured loses. This figure shows the difference between insured and economic losses over time in period 1970-2017.

This figure shows 10-year moving average of total economic losses and insurance losses too. We can see increasing trend in both cases but we can see increasing differences in these trends.

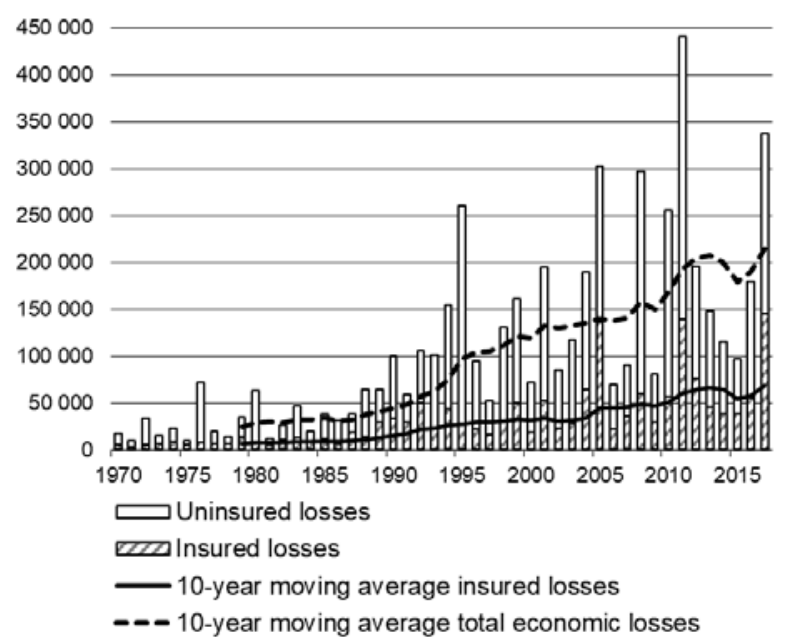

Source: Sigma Swiss Re, [4]

Fig. 2. Insured vs uninsured losses, $1970-2017$, in USD billion at 2017 prices

Catastrophe modelling helps insurers and reinsurers assess the potential losses caused by natural and manmade catastrophes. The Pareto model is very often used as a basis for Excess of Loss quotations as it gives a pretty good description of the random behaviour of large losses [5]. Especially quantile methods provide an appropriate and flexible approach to the probability modelling needed to obtain well-fitted tails [6-7]. Application of quantile based conceptual modelling methods has its foundation in the Order statistics theory [8].
Extreme value theory (EVT) [9-11] is a promising class of approaches to modelling catastrophe losses. Although originally utilised in other fields such as hydrology or operational risk [12]. There are two main kinds of models in EVT: block maxima models and peak over threshold (POT) models. More traditional models are Block maxima models which are for the largest observations collected from large samples observations. The whole sample is divided into equal non-overlapping time intervals and the biggest loss from each interval is used for modelling [13-17]. In the more modern approach using POT model (or the threshold exceedances model) the large enough threshold is determined and the observations above are considered [18-21]. The Extreme value methods do not predict the future with certainty, but they do offer models for explaining the extreme events we have seen in the past. These models are not arbitrary but based on rigorous mathematical theory concerning the behaviour of extrema [22-24].

For the purposes of this paper, the Block maxima model has been chosen based on real data of insured losses of natural catastrophes published by Swiss Re Sigma [1-4].

\section{Block Maxima Models}

The block maxima models are models for the largest observations collected from large samples of identically distributed observations.

The Fisher-Tippett theorem [22] is the fundamental result in Extreme Value Theory (EVT) and can be considered to have the same status in EVT as the central limit theorem has in the study of sums. The theorem describes the limiting behaviour of appropriately normalized sample maxima.

Suppose catastrophe losses are denoted by the independent, identically distributed random variables $X_{1}, X_{2}, \ldots$, whose common distribution function is $F_{X}(x)=P(X \leq x)$, where $x>0$.

Extreme Value Theorem [9]: Suppose $X_{1}, X_{2}, \ldots$ are independent, identically distributed with distribution function $F_{X}(x)$. If there exist constants $c_{n}>0$ and $d_{n} \in R$ such that

$$
\frac{M_{n}-d_{n}}{c_{n}} \rightarrow Y, \quad n \rightarrow \infty
$$

\section{Error! Bookmark not defined.}

where $M_{n}=\max \left(X_{1}, \ldots, X_{n}\right), Y$ is non-degenerate with distribution function $G$. Then $G$ is of one the following types:

1. Gumbel

$$
\Lambda(x)=\exp \left\{-\exp ^{-x}\right\}, \quad x \in R
$$

2. Frechet

$$
\Phi_{\alpha}(x)= \begin{cases}0 & x \leq 0 \\ \exp \left\{-x^{-\alpha}\right\} & x>0\end{cases}
$$


3. Weibull

$$
\Phi_{\alpha}(x)= \begin{cases}\exp \left\{-x^{-\alpha}\right\} & x<0 \\ 0 & x \geq 0\end{cases}
$$

These three types of limiting distribution there are in standard form. We can parameterize them within the location and scale families:

1. Gumbel

$$
\Lambda(x)=\exp \left\{-\exp \left[-\left(\frac{x-d}{c}\right)\right]\right\}, \quad x \in R
$$

2. Frechet

$$
\Phi_{\alpha}(x)= \begin{cases}0 & x \leq d \\ \exp \left\{-\left(\frac{x-d}{c}\right)^{-\alpha}\right\} & x>d\end{cases}
$$

3. Weibull

$$
\Phi_{\alpha}(x)=\left\{\begin{array}{l}
\exp \left\{-\left(\frac{x-d}{c}\right)^{-\alpha}\right\} \\
0<d \\
x \geq d
\end{array}\right.
$$

The generalized Gumbel, Frechet and Weibull families can be combined into a single family of the Generalized extreme value distributions (GEV) in the form

$$
G(x)=\exp \left\{-\left[1+\xi\left(\frac{x-\mu}{\sigma}\right)\right]^{-1 / \xi}\right\}
$$

where

$$
1+\xi\left(\frac{x-\mu}{\sigma}\right)>0
$$

It is straightforward to check the result by letting:

$$
\begin{aligned}
\alpha & =\frac{1}{\xi} \\
d & =\mu-\frac{\sigma}{\xi} \\
c & =\left\{\begin{array}{cl}
\frac{\sigma}{\xi} & \text { if } \xi>0 \\
-\frac{\sigma}{\xi} & \text { if } \xi<0
\end{array}\right.
\end{aligned}
$$

\section{Modelling of insured losses of natural catastrophes using block maxima model on real data}

For modelling by block maxima model we will use real data. The analysis focus on chronological list of 479 insured losses (in USD million) of natural catastrophes in time period from January 2010 to December 2016, published in Swiss Re Sigma 2011-2017. Fig. 4 shows times series plot of these real data.

Table 2 shows summary statistics of insured losses caused by natural catastrophes using our real date. In this table we can see that for example average, which is equal to 827.02 , is higher than median which is equal to 300 . The value of skewness is bigger than 10 and for example the value of kurtoses is really high - its value is 130.45 .

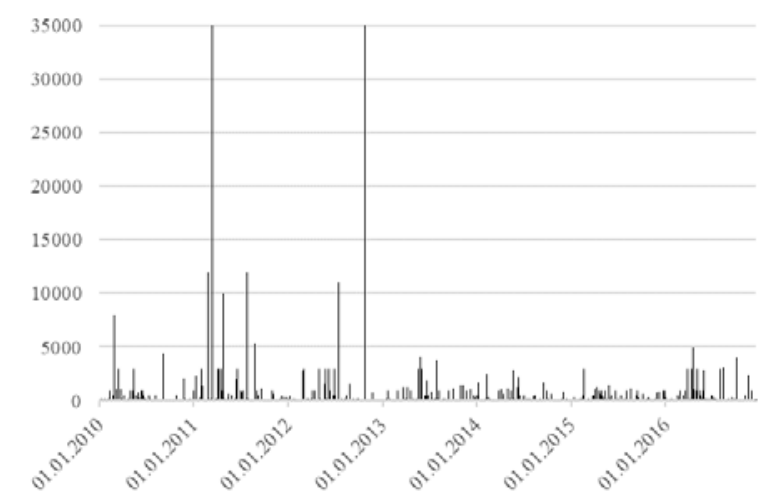

Source: Own processing by Sigma Swiss Re, No 1/2011-2/2017 Fig. 4. Chronologically arranged the insured losses of natural catastrophes in USD million.

We can compare value of lower and upper quartiles too. Summary statistics in Table 2 show that there are many small losses and a few very large values of losses. It follows that we need to find some long tail distribution that provides a suitable model for the variation amongst the catastrophe losses data.

Table 2. Summary statistics for insured losses of natural catastrophes.

\begin{tabular}{|c|c|}
\hline Count & 479 \\
\hline Average & 827.02 \\
\hline Median & 300 \\
\hline Dispersion & 6643828 \\
\hline Standard deviation & 2577.56 \\
\hline Coefficient of variation & 311.67 \\
\hline Skewness & 10.46 \\
\hline Kurtosis & 130.45 \\
\hline
\end{tabular}




\begin{tabular}{|l|c|}
\hline Upper quartile & 100 \\
\hline Lower quartile & 649 \\
\hline
\end{tabular}

Source: Own calculations

The catastrophe losses data presented by Fig. 4 we have divided into $n$ blocks (Table 3) of essentially equal size $N$. For this part of modelling we have used spreadsheet MS Excel.

Table 3. Number of blocks and values in the blocks.

\begin{tabular}{|c|c|}
\hline Number of blocks (n) & $\begin{array}{c}\text { Number of values in the } \\
\text { block }(\boldsymbol{N})\end{array}$ \\
\hline 5 & 95 \\
\hline 10 & 47 \\
\hline 15 & 31 \\
\hline 20 & 23 \\
\hline 25 & 19 \\
\hline 30 & 15 \\
\hline
\end{tabular}

Source: Own calculations

For these blocks of date we had modelling generalised extreme value distribution (GEV). We had used the software Statistica 12 for estimation of parameters of this distribution. Estimated value of parameters of GEV using formulas (1) and (2) for different blocks of data shows table 4 .

Table 4. Results of block maxima modelling.

\begin{tabular}{|c|c|c|c|c|}
\hline $\boldsymbol{n}$ & $\begin{array}{c}\text { Parameter } \\
\boldsymbol{g}\end{array}$ & $\begin{array}{c}\text { Parameter } \\
\boldsymbol{\mu}\end{array}$ & $\begin{array}{c}\text { Parameter } \\
\boldsymbol{\sigma}\end{array}$ & $\begin{array}{c}\boldsymbol{p} \text {-value of } \\
\text { Kolmogorov- } \\
\text { Smirnov test }\end{array}$ \\
\hline $\mathbf{5}$ & 0.6806 & 963.42 & 843.67 & 0.2474 \\
\hline $\mathbf{1 0}$ & 0.6685 & 1614.34 & 1348.23 & 0.5305 \\
\hline $\mathbf{1 5}$ & 0.7188 & 2016.51 & 1681.28 & 0.5504 \\
\hline $\mathbf{2 0}$ & 0.7887 & 2603.81 & 1915.22 & 0.4894 \\
\hline $\mathbf{2 5}$ & 0.7121 & 3168.59 & 2432.64 & 0.9097 \\
\hline $\mathbf{3 0}$ & 0.8909 & 3037.96 & 2405.69 & 0.8257 \\
\hline
\end{tabular}

Source: Own calculations
In this table 4 we can see $p$-values of KolmogorovSmirnov tests too. We can see the highest $p$-value for blocks for 25 values: $p=0.9097$. This model represent the best fit our data with the model GEV. This situation we can show in the next graph - Fig. 5. This figure shows GEV and empirical distribution function with $95 \%$ confidence interval of this distribution. We can see good fit for our data with our model.

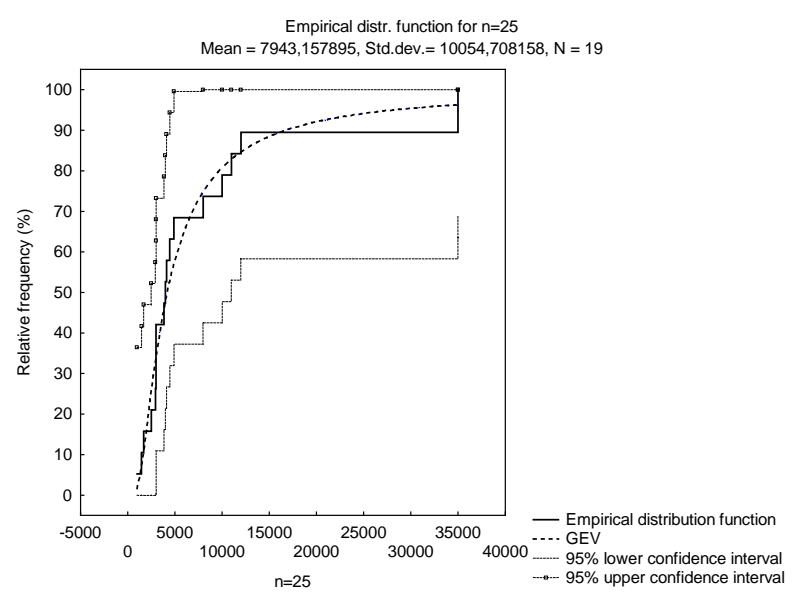

Source: Own processing

Fig. 5. GEV distribution fitted to block maxima for $n=25$

For the best estimated GEV model for $n=25$ we can calculate quantiles. Some of these quantiles shows table 5. By these value we can estimate, that for example in the future $50 \%$ insurance extreme losses of natural catastrophes exceed 4632.03 million USD and $1 \%$ exceed 39104 million USD.

Table 5. Quantiles of fitted GEV for block maxima model for $n=25$.

\begin{tabular}{|c|c|}
\hline Quantiles & GEV \\
\hline 0.50 & 4632.03 \\
\hline 0.75 & 9586.18 \\
\hline 0.90 & 17118.30 \\
\hline 0.95 & 23344.90 \\
\hline 0.99 & 39104.00 \\
\hline
\end{tabular}

Source: Own calculations

\section{Conclusion}


Catastrophic events have a huge impact on society as a whole. We can observe a growing trend in both the number of catastrophic events as well as in total and insured losses. Insurance and reinsurance undertakings must be prepared to pay for insured losses as a result of catastrophic events. A number of methods are used to help estimate and refine future claims cover. The block maximum method is one of these methods. Based on this method, this article presented its use on real data on insured losses caused by natural catastrophes from the period 2010-2016. Finding the appropriate distribution GEV and by estimating the parameters of this distribution it can be calculated its quantiles. The results of our real-time data analysis have shown that insurance and reinsurance companies can expect insured losses in the future, which in $50 \%$ exceed 4632.03 million USD, in $10 \%$ of the insured losses exceed 17118.3 million USD and in 1\% even more than 39104 million USD. This information is very important for risk management as it is one of the bases for calculating and adjusting premiums.

\section{Acknowledgement}

The authors are thankful to the Student Grant Competition of the University of Pardubice No. SGS_2018_012, titled "Using of big data sets for management of selected risks in public and financial sector" for financial support to carry out this research.

\section{References}

1. Sigma No 2/2015: Natural catastrophes and manmade disasters in 2014, Swiss Re [online]. Available on:

http://media.swissre.com/documents/sigma2_2015_ en_final.pdf

2. Sigma No 1/2016: Natural catastrophes and manmade disasters in 2015. Swiss Re [online]. Available on:

http://institute.swissre.com/research/overview/sigma /1_2016.html

3. Sigma 2/2017: Natural catastrophes and man-made disasters in 2016: a year of widespread damages. Swiss Re [online]. Available on: http://institute.swissre.com/research/overview/sigma /2_2017.html

4. Sigma No 1/2018: Natural catastrophes and manmade disasters in 2017: a year of record-breaking losses. Swiss Re [online]. Available on: http://institute.swissre.com/research/overview/sigma /1_2018.html

5. V. Pacáková, J. Gogola, Pareto Distribution in Insurance and Reinsurance. Conference proceedings from 9th international scientific conference Financial Management of Firms and Financial Institutions, VŠB Ostrava (2013)

6. P. Jindrová, L. Sipková, Statistical Tools for Modeling Claim Severity. Conference proceeding from 11th International Scientific Conference on European Financial Systems 2014. Location:
Lednice, Masaryk University Brno, Czech Republic (2014)

7. W.G. Gilchrist, Statistical modelling with quantile functions. London: Chapman \& Hall (2000)

8. H. A. David, H. N. Nagaraja, Order Statistics, 3rd ed. USA: John Wiley \& Sons (2003)

9. A. J. McNeil, Estimating the Tails of Loss Severity Distributions using Extreme Value Theory. ETH Zentrum, Zürich (1996) [online]. Available on: https:/ / www.casact.org/library/ astin/ v ol27no1/117.pdf

10. A. McNeil, Estimating the Tails of Loss Severity Distributions Using Extreme Value Theory. ASTIN Bulletin, 27(1) (1997)

11. P. Embrechs, C. Kluppelberg, T. Mikosch, Modelling Extremal Events for Insurance and Finance. Springer, Berlin (1997)

12. A. Brdar Turk, A Quantitative Operational Risk Management Model, Transactions on Business and Economics, Issue 5, Volume 6 (2009)

13. P. Jindrová, V. Pacáková, Probability Models of Natural Catastrophe Losses. In Proceedings of the 4th International Conference on Mathematical, Computational and Statistical Sciences (MCSS'16), Barcelona (2016)

14. P. Jindrová, M. Papoušková, Modelling insured catastrophe losses. Proceedings of the 10th Professor Aleksander Zelias International Conference on Modelling and Forecasting of SocioEconomic Phenomena, Zakopane (2016)

15. P. Jindrová, R. Jakubínský, Significance and possibilities of major accident insurance. E \& $M$ EKONOMIE A MANAGEMENT, 18, Issue 4 (2015)

16. V. Pacáková, L. Kubec, Modelling of catastrophic losses. Scientific Papers of the University of Pardubice, Series D, Vol. XIX, No. 25 (2012)

17. V. Pacáková, P. Jindrová, T. Musil, Quantification of risks of natural catastrophes. 8th International Scientific Conference on Managing and Modelling of Financial Risks, Ostrava (2016)

18. A. Davison, R. Smith, Models for exceedances over high thresholds, Journal of the Royal Statistical Society, Series B, No. 52 (1990)

19. V. Skřivánková, A. Tartal'ová, Catastrophic Risk Management in Non-life Insurance. In E\&M Economics and Management, No 2 (2008)

20. H. Zhongxian, Actuarial modelling of extremal events using transformed generalized extreme value distributions and generalized Pareto distributions, Doctoral thesis, The Ohio State University (2003) [online]. Available on: http://www.math.ohiostate.edu/history/phds/abstracts/pdf/Han.Zhongxian. pdf.

21. V. Pacáková, D. Brebera, Loss Distributions and Simulations in General Insurance and Reinsurance. International Journal of Mathematics and Computers in Simulation. NAUN, Volume 9, (2015)

22. R. Fisher, L. Tippett, Limiting forms of the frequency distribution of the largest or smallest 
member of a sample, Proceedings of the Cambridge Philosophical Society 24 (1928)

23. A. Balkema, L. de Haan, Residual life time at great age, Annals of Probability, 2 (1974)

24. J. Pickands, Statistical inference using extreme order statistics, The Annals of Statistics, 3 (1975) 